\title{
THE INFLUENCE OF DESIGN ON COMPANIES' INCREASE IN INCOME, MARKET SHARE OR BRAND VALUE
}

\section{- Jan Kramolis, Eva Svirakova}

\begin{abstract}
The main purpose of this paper is to focus on the awareness of SMEs of the influence of design on their business as well as on the performance of the company in the context of increased competitiveness. What economic indicators do design influence? Can they facilitate direct profit increases or just sales increases (turnover)? Can design factors affect long-term goals such as market share or brand value growth?

The research approach is based on theoretical sources as well as empirical studies conducted on design management and its relationship to a company's profits. Two research questions verifying the thesis were statistically tested at a significance level of 0.05 . A statistical search was also undertaken seeking to determine a dependence between how much companies expect to increase profits as well as brand value (achieving a competitive advantage) based on design elements.

The practical implications of the research were shown to confirm the thesis and unequivocally support the significant impact of design on the economic results of SMEs. This effect was shown especially in increased brand value, but also by profit as well as sales growth, all factors which are of high importance to businesses.

This, however, is not the primary focus of the article. The originality of this contribution lies primarily in the freshness of the data received, i.e. in the context of the current situation in the economy. It is commonly believed among practitioners of Product Life Cycle Theory that it is optimal for companies to invest in innovation (e. g. design) in the third phase, thus it is crucial that firms are (made) aware that design factors affect their economic goals, and to determine to what extent companies accept the reality of these effects. To meet these goals, we also considered profit maximization from the point of view of microeconomic theory, which is undoubtedly reflected in the formation of corporate goals, e.g. as measured by how design influences the four economic indicators of a company.
\end{abstract}

Keywords: design, design management, market share, profit, brand value, sales, design and competitiveness JEL Classification: D25, L21, M21, O31

Received: May, 2019

1st Revision: November, 2019

Accepted: November, 2019 


\section{INTRODUCTION}

Concepts related to profit (profit maximization) represent a pervasive theme in microeconomic theory. Issues influencing profitability are unquestioningly critical to companies. Nevertheless, the aim of the present article is not to further analyze profit as such, but the practical connection of design in general and of management design to profitability. Bruce \& Bessant (2002) have published findings outlining the main advantages of design management in the following ways: increasing profit by increasing sales or by decreasing manufacturing costs, increasing market share, gaining a competitive advantage, revamping mature and failing products, providing a strategy for growth, and, finally, design in regards to launching a new product or service. Oakley (1990) also mentions the link between design and business goals, i.e. valuing design considerations as a primary management goal in connection with a growth strategy. Design factors in relation to business competitiveness have been shown to play an essential role in economic prosperity (Kramoliš \& Staňková, 2017). In this context, a number of other aspects must be mentioned, the first of which may be alternative forms of economic performance from the perspective of a company. Most often performance is evaluated in terms of sales, an easily measurable factor. In addition, long-term, difficult-to-measure targets such as increases in brand value and in market share can also be considered in this context. All of these concepts are closely related to competitiveness goals that design, seen as innovation, can effectively help to achieve or even surpass.

\section{THEORETICAL BACKGROUND}

A properly managed design system can greatly enhance the development of a diverse, high-quality and extensive product portfolio for a company. Design can also be seen as an innovation process with the goal of linking the aesthetic and functional aspects of a proposed product, service, marketing tool or internal process within a company. In many cases, a company's investments in design are associated with research and development (R\&D) departments. Precise, sophisticated and effective design does not merely entail art; it is a business trigger that helps companies to prosper. In today's business climate, it is clear that R\&D must be justified as a profit-generating activity, i.e. R\&D expenditures must be evaluated in business terms in order to earn management support. The contributions made by R\&D are evaluated by top management according to the same criteria used for the rest of the organization - profitability. (Whaley \& Williams, 1971).

The maximization of profits is the main goal of many organizations. Researchers have described how crucial it is that factors affecting profitability of line designs should be more clearly identified, more thoroughly investigated, and more closely reflected in future management models. (Hazir et al., 2014). Keen \& Standish (2006) also refer to maximizing profits within the target industry, i.e. in terms of structure and competition. A similar typical microeconomic concept is the so-called "profits-oriented" approach, which is specific to most companies in the short and long term (Whaley \&Williams, 1971).

Design also plays an important role in starting a business, with Belás et al. (2016) determining that the most important motive for starting a business that of money, followed by other motives. The money motive is extremely important for the youngest entrepreneurs, with the importance of this motive decreasing with the advancing age of those in business. In the new, turbulently 
evolving international markets, the capacity for innovation and rapid changes triumphs. Globalization itself creates enormous pressure on organizations. SMEs must better develop products, understand the risks and opportunities in the market, as well as ensure their own sustainability (Kozubíková et al., 2015).

The scales of design sophistication (Žáková et al., 2015) which follow represent four different levels of intensity. These scales range from a purely aesthetic perspective (the "last touch") to the view of design as a compound influence on the entire production process (maximizing product quality and reliability while minimizing production and distribution costs, knowledge from market research and customer requirements, marketing and branding, etc.). Žáková et al. (2015) describe how the highest level of design implementation in a company shows its saturation point at the level "design as innovation." Briefly, this use of design can recommend and achieve a complete reconstruction of the whole company, or of a number of its essential business goals. Corporate managers know that they can measure the effects of design in terms of economic reports, with Braga (2016) examining the relationship between commercial success, competitive advantage, economic performance and design in order to demonstrate benefits that design can generate for companies. However, the reasons to invest in design are not reduced to enhancing commercial success in companies. Qualitative and quantitative dimensions along with variables concerning the value of design have also been defined by Braga (2016). This theory contains a perspective of different groups (users, companies and society) and domains reported (economics, marketing, business, management, design).

Mozota (2006) deals with the topic of design as a competitive edge. The author measures the impact of design on products, classifying the reasons for launching new products with the tacit knowledge of design. According to Bruce et al. (1999), small companies have a range of business needs for design, but show varying levels of awareness and competency to manage design effectively. A study by Roy \& Potter (1993) confirms the finding that graphic design projects are significantly more likely to be profitable than projects involving product design expertise or projects involving engineering alone or engineering plus industrial design.

Beverland et al. (2015) highlight two key implications for brand managers, recognizing the need for design thinking and organization in a way to achieve brand ambidexterity. The researchers define the type of design thinking associated with branding, focusing primarily on maintaining a strong relational interconnectivity among a company's image, brand and design.

Best (2015) put forth the Product Life Cycle Theory (PLC), in a publication focused on an analysis of Design Management. The specific enrichment from design comes in the ripeness phase, during which a company should already be considering product innovation and planning a new redesign or product facelift. If design issues are left to be dealt with until a company is threatened with bankruptcy, the company may not be able to manage to introduce the design-innovated product into the market in time, i.e. the company would not have sufficient time or money to devote to design issues as the focus is primarily on survival in the market. 


\section{RESEARCH OBJECTIVE, METHODOLOGY AND DATA}

\subsection{Objective}

The main purpose of this paper is to focus on the awareness of SMEs of the influence of design on their business as well as on the performance of the company. The first step in achieving this research goal is to determine what companies actually expect from design, which will be described in this background section.

This research, which took place between December 2018 and January 2019, was conducted electronically by team members of a project (TL02000255). The research area was conducted by having closed questions with four options and a four-point scale. Companies had to choose one of the options when completing the questionnaire. The questionnaire was designed (for the respondent to provide a certain tendency) by making a four-point scale (compared to the classic 5-point scale). Table 1 shows companies that completed the research questionnaire.

Tab. 1 - Target group characteristics: Business size distribution - Number of employees.

Source: own research

\begin{tabular}{|l|l|l|l|l|l|l|l|}
\hline $\begin{array}{l}\text { Target output } \\
\text { variable }\end{array}$ & $n$ & relative & $\begin{array}{l}\text { propor- } \\
\text { tion }\end{array}$ & $\begin{array}{l}\text { Business size } \\
\text { variable }\end{array}$ & $n$ & relative & proportion \\
\hline B2C & 93 & $46.73 \%$ & 0.47 & $\begin{array}{l}\text { XS } \\
(5-10 \text { empl. })\end{array}$ & 10 & $5.71 \%$ & 0.05 \\
\hline B2B & 87 & $43.72 \%$ & 0.44 & $\begin{array}{l}\text { S } \\
(11-50 \text { empl. })\end{array}$ & 110 & $62.86 \%$ & 0.63 \\
\hline B2G & 19 & $9.55 \%$ & 0.09 & $\begin{array}{l}\text { M } \\
(51-250 \text { empl. })\end{array}$ & 54 & $30.86 \%$ & 0.31 \\
\hline
\end{tabular}

The largest group in the study group is the one of B2C companies (almost half of the sample). The smaller part operates on B2B principles. So, we can talk about a well-balanced sample where both major areas are relatively represented in balance.

As for the size of the companies, the smallest companies with the number of employees 11-50 were predominant (63\% of the sample), and then the medium-sized companies with 50-250 employees (31\% of the sample). Very small businesses are represented by just less than $6 \%$. To identify the size of companies with regard to employees, variables were assigned, namely: XS = 5-10 employees; $\mathrm{S}=11-50$ employees; $\mathrm{M}=$ 51-250 employees.

At the same time, it is necessary to add that the addressed companies (research sample) were chosen after meeting these parameters:

1. each firm is a producer of products that is able to modify the design or packaging of the products;

2. each firm has the potential to employ design marketing communications materials;

3. each firm offers services (banking, insurance) in which design can be used;

4. each firm recognizes that it is in a competitive environment and are searching ways toward prosperity by differentiating products by design. 


\subsection{Research Questions}

Based on the objectives set in the research area, two research questions (RQ) can be established, the validity of which can be measured and tested using statistical tools.

$\mathrm{RQ}_{1}$ : Above all, companies expect an increase in Brand Value caused by design.

$\mathrm{RQ}_{2}$ : Which companies (in terms of size) most expect a profit increase caused by design.

The first research question assumes that the company is expecting an increase in Brand Value (future competitive advantage), depending on how large the company is. Basically, it can be considered that these expectations can be significantly different. This area can be analyzed using a contingency table and a four-element spider chart. Furthermore, it is also necessary to perform basic statistical calculations of the examined sample. The statistical evaluations of the set of investigated data by indicators are: Mean, Standard Deviation $(s)$ and Variance $\left(s^{2}\right)$.

As for the second question, $p$-value and the independence test Two-way $\chi^{2}$ calculation for each variable will be used for verification. With these tests, $\chi^{2}$, Degrees of freedom $(D F)$, $p$-value values will be calculated. Dependency testing will be based on the 0.05 significance level.

\subsection{Methodology}

The resulting data file was then cleared of all invalid and incomplete records, with the final data set used in the compilation containing 175 valid records. A research questionnaire was administered to hundreds of companies. Data from the questionnaires were processed in Microsoft Excel using pivot tables.

The question analyzed contained a range of four values, the importance of which is defined in the table below. The first column of the table is the value that was assigned to the individual record in the research data table. The second column contains a brief description of the value and the third column is a short description of the one-word form.

Tab. 2 - Assigned value of the research question and its definition. Source: own research

\begin{tabular}{|l|l|l|}
\hline Value & Description & Simplified (one word definition) \\
\hline 4 & $\begin{array}{l}\text { extremely important - it means that it is an } \\
\text { extremely important business for the company } \\
\text { without which they can not even imagine their } \\
\text { business }\end{array}$ & Extreme \\
\hline 3 & $\begin{array}{l}\text { relatively important - characterizing high impor- } \\
\text { tance for businesses, but it is not the primary issue }\end{array}$ & High \\
\hline 2 & $\begin{array}{l}\text { low importance - indicates that there are other and } \\
\text { more important priorities for companies where } \\
\text { the company can devote itself to this issue as for } \\
\text { the time and financial capacity matters }\end{array}$ & Low \\
\hline 1 & $\begin{array}{l}\text { completely unimportant - they are absolutely un- } \\
\text { important and superfluous for companies }\end{array}$ & None \\
\hline
\end{tabular}


Since we are researching four managerial / economic goals, variables have been created from these goals. These variables are listed and described in the table below. These variables can be found later in the article. It should be mentioned that brand value is usually closely linked to competitiveness.

Tab. 3 - Assigned variables. Source: own research

\begin{tabular}{|l|l|}
\hline Variable & Description of expectation \\
\hline$M S$ & Increase market share \\
\hline$S$ & Increase sales \\
\hline$P$ & Increase profit \\
\hline$B V$ & Increase brand value \\
\hline
\end{tabular}

As for the view of basic statistical indicators, the standard deviation (SD) was calculated, which shows how much the typical cases in the set of examined numbers differ from each other. Then, variance $\left(s^{2}\right)$, arithmetic mean, and median value were calculated. This enabled as to see up to what extent the typical cases vary within the set of examined values.

For a more precise visual representation of the measured results, the axis values in the spider charts were adjusted to intervals 2.0 to 3.0. For the visual interpretation of results in the spider chart, figures were assigned by having the variables MS, S, P, BV defined.

Based on the problem solution from above, there were established research questions (RQ). RQs were tested on the level of significance of $\alpha=0.05$. Every RQ was subject to the Pearson's chisquared $\chi^{2}$ test of independence (Hindls, 2007) for a contingent table, using IBM SPSS Statistics software. P-value and Excel software were used for the statistical evaluation of each RQ.

The value of the test-statistic is

$\chi^{2}=\sum_{i=1}^{r} \sum_{j=1}^{c} \frac{O_{i j}-E_{i j}}{E_{i j}}(1)$

$\chi^{2}=$ Pearson's cumulative test statistic;

$O_{i}=$ an observed frequency in a given contingency table;

$E_{i}=$ an expected (theoretical) frequency, asserted by the null hypothesis;

$r, c$ are the number of rows and columns in the table, respectively. (Hindls, 2007).

\section{RESULTS AND DISCUSSION}

\section{1 $\mathrm{RQ}_{1}$ - Above all, companies expect an increase in Brand Value caused by design}

These research issues assume that companies expect design to primarily increase the value of Brand Value (future competitive advantage). The total measured values from the research are visually interpreted by a four-point spider chart in Figure 1. This graph is based on the same principle as magic quadrangle known from macroeconomics (McGlamery, 1997). When interpreting, it is true that the larger the quadrangle, the better for company economics it is from the design perspective and its effect. 


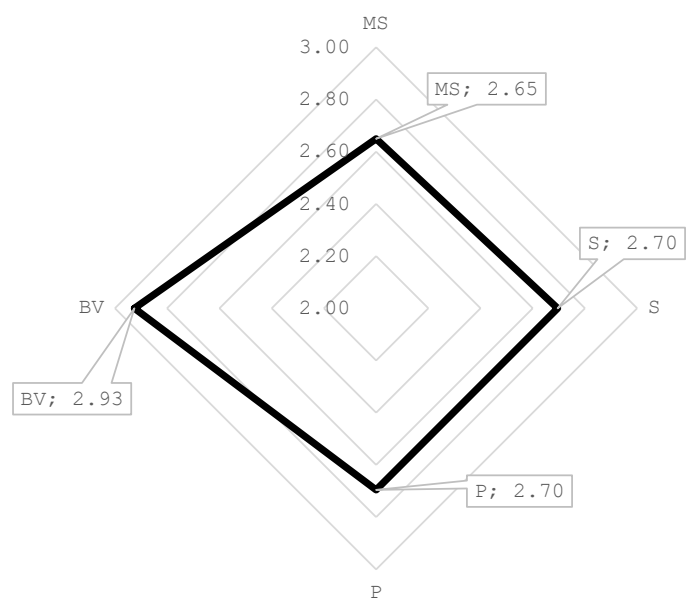

Fig. 1 - The impact of design on company variables - Spider chart. Source: own research

It can be seen from the above quadrangle (Figure 1) that the higher the values, the stronger the influence of design on a particular variable. The spider chart is modified from the original min: 1 and max: 4 to the selection of the most often values occurred for the best readability. Specifically, it is min: 2 and $\max 3.00$. The strongest value can be seen in the brand value (BV) variable with a value of 2.93 , which is $11 \%$ higher than the values of the sales $(\mathrm{S})$ and profit $(\mathrm{P})$ variables. The market share (MS) variable is 2.65 . Thus, the overall average would be 2.745 , indicating a strongly approaching value of 3 , which was defined as "quite important - characterizing high importance for businesses, but not a primary issue."

If we should evaluate it altogether: The highest importance of design ( $\max$ ) to the selected economic indicators for the company is the value of 4.0. This value was not measured in any of the variables examined. Conversely, the lowest value (min) is 1.0 and it was not measured in either case either. The selected statistical indicators were calculated for a more detailed examination of the measured data file. The following table lists the statistical indicators: Mean, Standard Deviation (s) and Variance (s2).

Tab. 4 - Statistical evaluation of the data file. Source: own research

\begin{tabular}{|l|l|l|l|l|}
\hline Statistics indicators / variable & MS & S & P & BV \\
\hline Mean & 2.646 & 2.691 & 2.691 & 2.92 \\
\hline Standard Deviation $(s)$ & 0.7429 & 0.8884 & 0.8884 & 0.8539 \\
\hline Variance $\left(s^{2}\right)$ & 0.5519 & 0.7893 & 0.7893 & 0.7292 \\
\hline
\end{tabular}

Min: 1; Max: 4; Count: 175; Median: 3; Mode: 3.

The researched data file achieves a mean variance of $0.6-0.8$, suggesting good data consistency. The standard deviation from the file of all the researched records in the companies shows how much the typical cases in the file of the researched numbers differ from each other. A value of 0.7-0.9 indicates that the elements of the file are usually very similar to each other, signaling relatively small differences. 
As it is an aggregate view of the entire RQ, detailed analyzes of this issue were created from the size of companies perspective. Figure 2 shows the concrete differences clearly and in more detail.

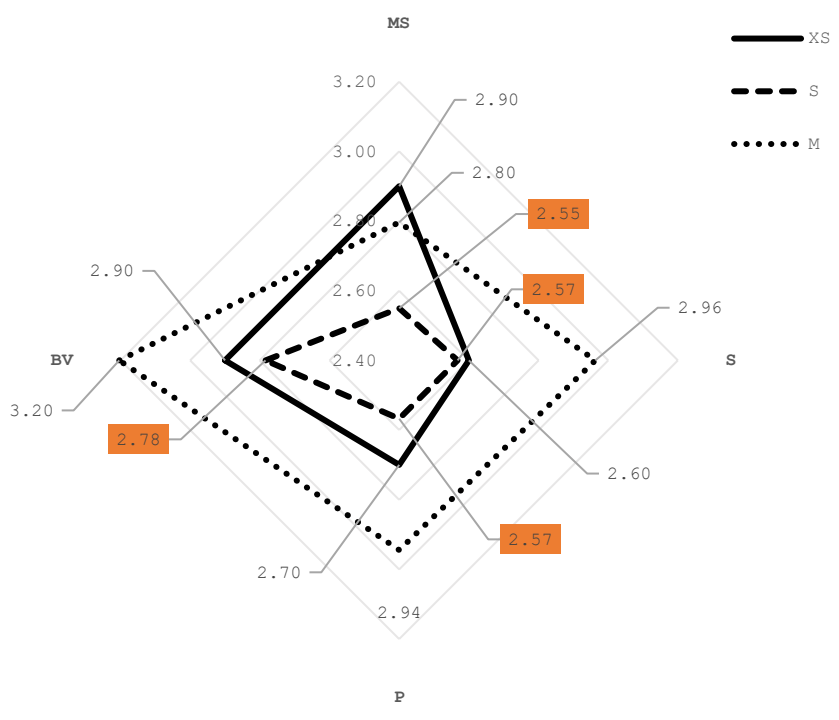

Fig. 2 - Spider chart: The influence of design on selected corporate results with regard to the business size. Source: own research

Figure 2 shows that the higher the values, the stronger the influence of the design on a particular variable. The spider chart is modified from the original min: 1 and max: 4 to the selection of the most often values occurred for the best readability. Specifically, it is min: 2.40 and max: 3.20. The strongest value can be seen in the brand value (BV), the variable of 3.20. Other variables for this size of companies (sorted by size) are $2.96 \mathrm{~S} ; 2.94 \mathrm{P} ; 2.80 \mathrm{MS}$. These companies feel the impact of design from the selected variables mainly in the market share.

Evaluated collectively, the highest importance of design (max) to the selected economic indicators for the company is the value of 4.0. This value was not measured in any of the variables examined. Conversely, the lowest value ( $\mathrm{min}$ ) is 1.0 and it was not measured in either case either. The selected statistical indicators were calculated for a more detailed examination of the measured data file. The following table lists the statistical indicators: Mean, Standard Deviation $(s)$ and Variance $\left(s^{2}\right)$.

For a specific quantitative view, see Table 5, in which the individual variables with the calculated value corresponding to the size of the company are shown, including two columns with the statistical indicators arithmetic mean and median. 
Tab. 5 - Business size sample of data according to the increase variable/mean values. Source: own research

\begin{tabular}{|l|l|l|l|l|l|l|}
\hline & MS & S & P & BV & Mean & Median \\
\hline XS & 2.90 & 2.60 & 2.70 & 2.90 & 2.78 & 3 \\
\hline S & 2.55 & 2.57 & 2.57 & 2.78 & 2.62 & 3 \\
\hline M & 2.80 & 2.96 & 2.94 & 3.20 & 2.98 & 3 \\
\hline Mean & 2.75 & 2.71 & 2.74 & 2.96 & & \\
\hline
\end{tabular}

Thus, the overall average would be 2.98 for medium-sized companies (M), which is rounded to the value of 3 . This finding was defined as "relatively important - characterizing high importance for businesses, but not a primary issue."

Showing a slightly lower importance of design in relation to the selected economic indicators, the mean is 2.78 for the companies with 1-10 employees, with even a slightly lower value of 2.62 found in the companies with 11-50 employees. In general, these two categories of companies can also be spoken of at a level close to 3, which was defined as "relatively important - characterizing high importance for businesses, but not a primary issue."

\subsection{RQ2 - Which companies expected the highest increase in profit due to design?}

Research Question No. 2 facilitated a deeper investigation into the measured values and the search for dependencies with respect to company size. Specifically, the dependence of the variable BV and $\mathrm{P}$ was searched for in the Two-way $\chi^{2}$ calculation. The following two tables form the data for the statistical testing itself, with the first row containing the variables defining the size of the companies. The first column shows the design strength of the selected economic indicator $(\mathrm{BV}, \mathrm{P})$, in which "extreme" denotes a very strong effect and "none" no effect. The variables in this column have already been defined in Table 2 in the "one-word description" column.

Tab. 6 - Search for independence between BV and company size. Source: own research

\begin{tabular}{|l|l|l|l|l|}
\hline \multicolumn{2}{|l|}{ Two-way $\mathrm{X}^{2}$ calculation for BV } \\
\hline \multirow{4}{*}{ Extreme } & XS & S & M & \\
& 2.57 & 22 & 21 & \\
& $(0.13)$ & $(1.50)$ & $(3.64)$ & 45 \\
\hline \multirow{4}{*}{ High } & 6 & 51 & 26 & \\
& 4.74 & 52.65 & 25.61 & 83 \\
& $(0.33)$ & $(0.05)$ & $(0.01)$ & \\
\hline \multirow{4}{*}{ Low } & 1 & 30 & 4 & \\
& 2.00 & 22.20 & 10.80 & 35 \\
\hline \multirow{3}{*}{ None } & $(0.50)$ & $(2.74)$ & $(4.28)$ & \\
\hline & 1 & 8 & 3 & \\
& 0.69 & 7.61 & 3.70 & 12 \\
& $(0.14)$ & $(0.02)$ & $(0.13)$ & \\
\hline & 10 & 111 & 54 & 175 \\
\hline
\end{tabular}


Statistical testing results in $\chi^{2}=13.482, D F=6, \chi^{2} / D F=2.25$, where the $\mathrm{p}$-value at the defined significance level is $\mathrm{P}\left(\chi^{2}>13.482\right)=0.0360$. Therefore, the value is less than 0.05 , i.e. the elements are independent of each other. Finally, the result of this RQ is that dependency has not been confirmed.

Tab. 7 - Search for independence between P and a company size. Source: own research

\begin{tabular}{|l|l|l|l|l|}
\hline \multicolumn{2}{|l|}{ Two-way $\mathrm{X}^{2}$ calculation for BV } \\
\hline & XS & S & M & \\
\hline Extreme & 0 & 15 & 18 & 33 \\
& 1.89 & 20.93 & 10.18 & \\
& $(1.89)$ & $(1.68)$ & $(6.00)$ & \\
\hline High & 7 & 46 & 19 & 72 \\
& 4.11 & 45.67 & 22.22 & \\
& $(2.02)$ & $(0.00)$ & $(0.47)$ & \\
\hline Low & 3 & 37 & 13 & 53 \\
& 3.03 & 33.62 & 16.35 & \\
& $(0.00)$ & $(0.34)$ & $(0.69)$ & \\
\hline None & 0 & 13 & 4 & 17 \\
& 0.97 & 10.78 & 5.25 & \\
& $(0.97)$ & $(0.46)$ & $(0.30)$ & \\
\hline & 10 & 111 & 54 & 175 \\
\hline
\end{tabular}

Statistical testing results in $\chi^{2}=14.812, D F=6, \chi^{2} / D F=2.47$, where the $\mathrm{p}$-value at the defined significance level is $\mathrm{P}\left(\chi^{2}>14.812\right)=0.0218$. Therefore, the value is less than 0.05 , i.e. the elements are independent of each other. Finally, the result of this part of RQ is that dependency has not been confirmed.

The basic view of the quantities suggests that M companies after profit are shown at the highest level, followed by XS companies, with S the lowest. However, in terms of dependent variables, the chi-square statistic is 11.4072 , with the $\mathrm{p}$-value .076577 . The result is not significant at $\mathrm{p}<$ $.05 .=$ values are independent $=$ dependency does not exist.

\subsection{Evaluating RQs}

The first research issue $\left(\mathrm{RQ}_{1}\right)$ deals with how strongly design influences an increase in brand value with regard to the company size. The research has shown that the design itself increases brand value mostly in medium-sized companies, followed by very small companies, with the least in small companies.

The second research issue $\left(\mathrm{RQ}_{2}\right)$ explored the area of profit increase, i.e. if any dependence could be found between the increase in profit and the size of a company. Although the basic descriptive statistics (Table 6) indicate that medium-sized companies (M) after profit are shown the highest level, followed by very small companies, with small companies the lowest. In deeper statistical 
research, a dependency across the variables was sought, with these calculations determining that there was no dependence.

\section{CONCLUSION}

Our evaluation of the examined data showed that in all four economic goals of the company, the evaluation "relatively important" prevails, albeit with varying homogeneity. It is this value that highlights the importance for companies, although this is not the primary issue. In detail, design was shown to have the strongest impact out of the four examined options on brand value (BV), followed by profit (P) and sales (S) and, finally, market share (MS). This result can be evaluated and explained in the following manner: companies are aware of the fact that design works in the long run, and even though profit can be distorted by investment in design, and sales can be strongly influenced by aggregate demand in the economy, brand value has the strongest relationship to design. The effects of design are very difficult to measure, especially regarding how to cleanse corporate results from other influences in accordance with ceteris paribus theory. In their publication, the authors Kramoliš \& Staňkova (2017) pointed out the pitfalls of these calculations, with one solution being to quantitatively and accurately measure using the return on investment in design - payback period $\left(\mathrm{pBp}_{\mathrm{d}}\right)$, or the indicator $\mathrm{ROI}_{\mathrm{d}}$.

On the other hand, it cannot be said that companies consider the effects of design in terms of increases in sales, profits, and market share to be negligible. However, regarding the results in terms of the brand value (which is associated with competitiveness), the effects are slightly lower.

The key explanation is that companies are well aware that design affects all four economic indicators. Future research could show a comparison of development over time as well as indicate in more detail how companies specifically quantify these indicators.

Concerning the perception of profit growth with regard to design, it has been confirmed that profit is not of the highest priority along the lines of the same microeconomics logic of Keen \& Standish (2006): "Maximizing profit while ignoring what other firms do is rather like rowing a boat to a specific location while ignoring the wind and tides." It is quite understandable that pursuing profits can be very demanding and even traumatic for a company. Above all, this stress affects business managers and the marketing department, who in turn attempt to bring down costs. Nevertheless, it would be a mistake to reduce costs by neglecting design innovation, all the more so today as the Czech economy is currently in a period of boom. When it comes to the Product Life Cycle Theory, it is essential to innovate with design in Phase 3 (Kramoliš, 2016) as long as companies have the capital available. If we were to go back to the research question and describe it in more detail, minor differences in the perception of profit increases caused by design could be claimed, as well as the finding that medium-sized companies value design the most, followed by very small companies and then small companies.

In conclusion, we can consider the results of both examined areas positively from a critical managerial point of view in terms of the awareness of the power of design with respect to the market situation and growing competition. Many Czech companies have become well-known and successful over the past 10 years thanks to the quality and timeless design of their products. Despite the fact that these products are usually much more expensive than other products on the market, 
due to their design costs, these products have been positively evaluated on the market over time (i.e. by the growing demand for these products). Obviously, the success of design is also partly a result of the pricing policy, which is part of the Veblen effect theory (Bagwell \& Berheim, 1996), which completes the product value. It is precisely this kind of information about these companies that forms the market for certain "influencers" in the business sphere, as every company wants to be successful, and investing in design is one of many factors to make the company prosper in the long run. It is important to feature products with a long-term demand overhang, ideally internationally. The measures of quality, time and cost represent the three goals which cannot all be pursued at once with maximum effort for each, i.e. as put forth by Best (2015) in the triangle theory in which not all three "tops" can be achieved. In other words, in line with this theory it is not possible to obtain the highest possible quality of design in the shortest possible time while also maintaining minimum possible costs. Furthermore, increasing demands regarding both living environmental protection as well as the effective management of supply chains within particular industries also bring to bear great pressures on companies (Hart et al., 2016).

Within an adequate time frame and with sufficient capital investment, it is precisely systematic and sophisticated design management that can develop the expertise and ingenuity needed to create new products and services for companies as well as to refurbish and remarket existing brands. This emphasis on design can proceed in parallel with the concept of 1P marketing (Kramoliš \& Kopečková, 2013), which ultimately generates what has been termed marketing resonance, as defined by Keller (2009).

\section{Acknowledgements}

This paper was completed with the support of the Technology Agency of the Czech Republic (Project No.: TL02000255; A Managerial Model of Design Value for Competitiveness of SME in the Czech Republic)

\section{References}

1. Bagwell, L. S., \& Bernheim, B. D. (1996). Veblen effects in a theory of conspicuous consumption. The American Economic Review, 86(3), 349-373. Retrieved from www.jstor.org/ stable/2118201

2. Belás, J., Ključnikov, A., \& Smrčka, L. (2016). Motives for entrepreneurship: Case study from the world of SMEs. Scientific Papers of the University of Pardubice, Series D: Faculty of Economics and Administration. 16 (3), 5-17.

3. Best, K. (2015). Design management: managing design strategy, process and implementation. Bloomsbury: AVA publishing.

4. Beverland, M. B., Wilner, S. J., \& Micheli, P. (2015). Reconciling the tension between consistency and relevance: design thinking as a mechanism for brand ambidexterity. Journal of the Academy of Marketing Science, 43 (5), 589-609. https://doi.org/10.1007/s11747-015-04438

5. Braga, M. F. (2016). The value of design: an issue of vision, creativity and interpretation. 2016 Design Research Society 50th Anniversary Conference. 27-30 June 2016. Brighton. UK.

6. Bruce, M., \& Bessant, J. R. (2002). Design in business: Strategic innovation through design. Essex: Pearson education Limited. 
7. Bruce, M., Cooper, R., \& Vazquez, D. (1999). Effective design management for small businesses. Design studies, 20 (3), 297-315.

8. Hart, M., Taraba, P., \& Konečný, J. (2016). Sustainable manufacturing systems based on demand forecasting - supply chain sustainable growth. International Conference on Sustainable Design and Manufacturing. 191-202. Springer, Cham.

9. Hazır, Ö., Delorme, X., \& Dolgui, A. (2014). A survey on cost and profit oriented assembly line balancing. IFAC Proceedings Volumes, 47 (3), 6159-6167.

10. Hindls, R., (2007). Metody statistické analýzy pro ekonomy. 8th ed. Prague: Professional Publishing.

11. Keen, S., \& Standish, R. (2006). Profit maximization, industry structure, and competition: A critique of neoclassical theory. Physica A: Statistical Mechanics and Its Applications, 370 (1), $81-85$.

12. Keller, K. L. (2009). Building strong brands in a modern marketing communications environment. Journal of Marketing Communications, 15 (2-3), 139-155. https://doi. org $/ 10.1080 / 13527260902757530$

13. Kozubíková, L., Belás, J., Ključnikov, A., \& Virglerová, Z. (2015). Differences in the approach to selected constructs of entrepreneurial orientation in the SME segment regarding the selected socio-demographic factors. Transformations in Business and Economics, 14 (3), 333-355.

14. Kramoliš, J. (2016). The attitude of Czech companies towards design-comparative study of 2012 and 2014. Marketing and Management of Innovations, 2016 (2), 11-21.

15. Kramoliš, J., \& Kopečková, M. (2013). Product Placement: A smart marketing tool shifting a company to the next competitive level. Journal of Competitiveness, 5 (4), 98-114.

16. Kramoliš, J., \& Staňková, P. (2017). Design and Its Impact on the Financial Results of Enterprises (Based on Managers' Opinions). Journal of Competitiveness, 9 (2), 62-77.

17. McGlamery, P. (1997). MAGIC transaction logs as measures of access, use, and community. The Journal of academic librarianship, 23 (6), 505-510.

18. Mozota, B. (2006). The four powers of design: A value model in design management. Design Management Review, 17 (2), 44-53.

19. Oakley, M. (1990). Design management: A handbook of issues and methods. Oxford, UK: Blackwell Reference.

20. Roy, R., \& Potter, S. (1993). The commercial impacts of investment in design. Design studies, 14 (2), 171-193.

21. Whaley, W. M., \& Williams, R. A. (1971). A profits-oriented approach to project selection. Research Management, 14 (5), 25-37.

22. Žáková, E., Císař, J., Dohnalová, L., Faltus, J., Hadaš, J., Hejduk, M., Mošna, P., Nekolný, B., Peterka, I., Raabová, T., Sedláková, R., Sedmerová, Z., \& Skřivánek, J. (2015). Kulturní a kereativni primysly v Ceské republice. Prague: Arts and Theatre Institute. 


\section{Contact information}

Jan Kramolis, Ph.D.

Tomas Bata University in Zlin, Faculty of Management and Economics, Department of Economics

Czech Republic

E-mail:kramolis@utb.cr.

ORCID: 0000-0002-1687-8067

Eva Svirakova, Ph.D.

Tomas Bata University in Zlin, Faculty of Multimedia Communications, Department of Theoretical Studies Crech Republic

E-mail:svirakova@utb.cr.

ORCID: 0000-0002-7529-0255 